\title{
COMPLEXIDADE E TRANSDISCIPLINARIDADE: CONVITES PARA A COLABORAÇÃO E CORRESPONSABILIDADE EDUCATIVA
}

\author{
COMPLEXITY AND TRANSDISCIPLINARITY: INVITATIONS \\ FOR COLLABORATION AND EDUCATIONAL SHARED \\ RESPONSIBILITY
}
COMPLEJIDAD Y TRANSDISCIPLINARIEDAD: INVITACIONES
PARA LA COLABORACIÓN YLA RESPONSABILIDAD EDUCATIVA

\begin{abstract}
Andréia de Andrade Moraz ${ }^{1}$
Universidade do Oeste de Santa Catarina (Unoesc), Pesquisadora do Programa Observatório da Educação (Obeduc)

\section{Roque Strieder ${ }^{2}$}

Universidade do Oeste de Santa Catarina (Unoesc), Professor do Programa de Pós-Graduação em Educação (PPGEd); Pesquisador colaborador do Programa Observatório da Educação (Obeduc)
\end{abstract}

Resumo: Somos reféns de uma organização social enraizada em uma extensa lista de dispositivos de ordem, que geram grave crise pedagógica e educacional. Diante desse contexto e da lógica racional dos conhecimentos, e considerando a etimologia de complexus (o que é tecido junto), no trabalho indicamos a transdisciplinaridade como oportunidade de articular os elementos contraditórios desse "tecido junto" também no aspecto pedagógico e formativo. Fruto de reflexões teóricas, sugerimos a complexidade para reconhecer a emergência de diferentes níveis de realidades, seja das coisas do mundo, da vida, seja das organizações humanas, e como uma possibilidade para alargar a compreensão do real pela abertura e aceitação da presença auto-organizativa em cada ser humano. Concluímos: essa abordagem cria sensibilidade para a responsabilidade na transformação de si, do outro e do mundo.

Palavras-chave: Educação. Complexidade. Transdisciplinaridade. Colaboração.

\footnotetext{
${ }^{1}$ Mestre em Educação pelo Programa de Pós-Graduação em Educação (PPGEd) da Universidade do Oeste de Santa Catarina (Unoesc); Bolsista do Programa Observatório da Educação (Obeduc).

${ }^{2}$ Doutor em Educação pela Universidade Metodista de Piracicaba (Unimep); Mestre em Educação pela Universidade Federal de Santa Catarina.
} 
Abstract: We are hostages of a social organization rooted in a long list of order devices, that generate a serious pedagogical and educational crisis. Given this context and the rational logic of knowledge, and considering the etymology of complexus (what is built together), this work indicates the transdisciplinarity as an opportunity to articulate the contradictory elements of this "built together" also in the pedagogical and formative aspect. Result of theoretical reflections, we suggest the complexity to recognize the emergence of different levels of reality, considering things from the world, life and/or human organizations, and as a possibility to expand the understanding of the real by opening and acceptance of the self-organizing presence in each human being. We conclude: this approach creates sensibility to the responsibility in its own transformation as well as in the transformation of the others and the world.

Keywords: Education. Complexity. Transdisciplinarity. Collaboration.

Resumen: Somos rehenes de una organización social, basada en una larga lista de dispositivos que generan orden pedagógico serio y crisis de la educación. En este contexto y la lógica racional de los conocimientos y teniendo en cuenta la etimología de complexo "que está tejido en conjunto", el trabajo indica la transdisciplinariedad como una oportunidad para articular los elementos contradictorios de este "entrelazados", también en el aspecto educativo y formativo. El resultado de consideraciones teóricas, se sugiere la complejidad de reconocer la aparición de diferentes niveles de la realidad, si las cosas del mundo, la vida y / o las organizaciones humanas. Una posibilidad para ampliar el conocimiento de la verdadera apertura y la aceptación de la presencia de auto-organización en cada ser humano. Llegamos a la conclusión. este enfoque crea sensibilidad de la responsabilidad en la transformación de sí mismos, los demás y el mundo.

Palabras clave: Educación. Complejidad. Transdisciplinariedad. Colaboración.

\section{CONSIDERAÇÕES INICIAIS}

Planejamentos fechados, trabalho burocrático, exigências legais, metas e resultados e engessamento do currículo escolar são fatores que têm contribuído para uma regulação cada vez mais ampliada dos processos educativos. Esse engessamento acaba por minimizar as ricas possibilidades de ensino e aprendizagem, como experiências de vida, que podem ser construídas na escola. Por isso, a educação necessita de uma desorientação; pressupõe, portanto, o abandono de verdades normatizadas, 
estáticas e absolutas. Caminhos prontos, já construímos demais e sentimos na pele o fracasso que a rigidez de planos fechados podem ocasionar.

Se, como escreve Minayo (1991, p. 72), a ciência moderna, pela fragmentação do conhecimento, ignora "o ser humano como ponto de partida e de chegada", "desnaturaliza a natureza" e "desumaniza a humanidade", ela também promove a ruptura entre o conhecimento da natureza e o conhecimento do mundo social. Aprendemos a segmentar, a compartimentalizar e a isolar e dificilmente percebemos o mundo articulado, colaborativo e simbiótico. Precisamos educar nosso olhar para perceber as interconexões, para perceber que o todo em movimento significa implicações para um devir humano, interdependente desde o princípio.

Assim, temos como objetivo compreender como o pensamento complexo e a transdisciplinaridade podem contribuir para a efetivação de processos pedagógicos e formativos permeados pela colaboração e, então, de corresponsabilidade entre humanos e entre saberes. O humano é humano no acontecer da e em coletividade, e, nessas inter-relações estabelecidas, as pessoas têm a possibilidade de ensinar e aprender. A escola é essencialmente um lugar de relações, de encontros e diálogos, por isso é um campo fértil para uma "reforma de pensamento" que permita novas percepções sobre os conhecimentos, sobre a condição humana e sobre os processos de ensino e de aprendizagem (MORIN, 2004).

Diante das novas e imprevisíveis demandas educativas, este trabalho, fruto de investigações em referenciais teóricos, resulta em um convite para refletir sobre o pensamento complexo e as possibilidades de alargamento de contribuições pedagógicas pela abordagem transdisciplinar. Pulsa a necessidade de compreendermos e acolhermos a transdisciplinaridade como um convite para abandonar as visões simplistas e fragmentárias ainda presentes em espaços educativos.

Entendemos que aceitar a transdisciplinaridade possibilita navegar entre incertezas, colocar-se à disposição para pensar de forma processual ações pedagógicas e formativas amplas, abertas, flexíveis e colaborativas, em que os envolvidos se sintam corresponsáveis pelo processo.

\section{PENSAMENTO COMPLEXO: NAVEGANDO POR LUGARES SURPREENDENTES}

A humanidade encontra-se em constante processo de transformação, assim como a ciência que, da segurança nas verdades, reconhece a incerteza e aceita a complexidade das interdependências. A revolução da tecnociência equivale a uma 
revolução paradigmática com implicações profundas em diversos âmbitos da vida relacional humana, econômica, ambiental, política e educacional. Todos esses âmbitos, na atualidade, estão merecendo atenção e investigações, visando ampliar a compreensão das profundas interferências no modo de ser humano. Em particular, no campo educacional são amplos e inovadores os debates provocados por reflexões de reconhecimento dos limites do arcabouço simplista, presente nas teorias pedagógicas tradicionais cada vez mais insuficientes para explicações e compreensões das diversas realidades emergentes. Morin (1987, 1989, 1992, 1996, 2002, 2005), formulador do método $^{3}$ da complexidade, toma como ponto de partida a inadequação dos conhecimentos compartimentados para explicar as realidades e suas problemáticas polidisciplinares e multidimensionais. Morin é enfático ao afirmar a necessidade de uma reforma paradigmática do pensamento. Essa reforma do pensamento tem como desafio a compreensão de que visões fragmentadas e compartimentalizadas são insuficientes para conhecer realidades amplas e complexas. Focar o olhar sobre determinado fenômeno, a partir de uma posição fixa e objetiva, é cegar-se para outras tantas dimensões que envolvem os fenômenos. Para Morin, a forma objetiva e simplista é grave problema para conhecimentos mais extensivos, ou seja, a eliminação do observador isola e desconsidera sua participação no acontecer dos fenômenos.

Essa reforma do pensamento consiste na amplificação do reconhecimento e da compreensão da complexidade. Complexidade, segundo Morin (2003), é um desafio e não uma resposta ou uma receita para as problemáticas existentes na contemporaneidade. Para explicar o significado da complexidade, o autor vai às raízes etimológicas da nossa língua, o latim, em busca de sentidos que se perderam no decorrer dos tempos (GELATI, 2010). A palavra complexidade deriva do termo latino complexus e quer dizer o que está junto, o que é tecido junto. Concebe imaginários de uma trama de fios que se entrelaçam formando algo maior, um tecido. Na formação do tecido, os fios não se anulam, entrecruzam-se e mantêm sua singularidade, mas compõem uma nova unidade não mais na singularidade, mas na diversidade (MORIN, 2003).

$\mathrm{O}$ conceito de complexidade de Morin está indissociavelmente ligado à ideia de uma reforma do pensamento que possibilita compreender a dinâmica interdependente entre os fenômenos e, assim, pensar a multidimensionalidade presente

\footnotetext{
${ }^{3} \mathrm{O}$ método da complexidade, formulado por Morin, é composto por seis volumes, ou seja, O Método I: a natureza da natureza (Portugal: Publicações Europa-América, 1987); O Método II: A vida da vida (2. ed. Portugal: Publicações Europa-América, 1989); O Método III: o conhecimento do conhecimento (2. ed. Portugal: Publicações Europa-América, 1992); O Método IV: as ideias - a sua natureza, vida, habitat e organização (Portugal: Publicações Europa-América, 1996); O Método V: a humanidade da humanidade (Porto Alegre: Sulina, 2002); e O Método VI: ética (Porto Alegre: Sulina, 2005).
} 
nas interações. "Trata-se de procurar sempre as relações e inter-retro-ações entre cada fenômeno e seu contexto, as relações de reciprocidade todo/partes: como uma modificação do todo repercute sobre o todo e como uma modificação do todo repercute sobre as partes." (MORIN, 2004, p. 25).

Ainda influenciados pelo modelo cartesiano, a tendência é segmentar pressupondo a possibilidade de compreensão; certamente, na tranquilidade simplificadora, visualizar e experienciar a complexidade é incômodo e, para muitos, assustador. No seio da complexidade o considerado real e absoluto se fragiliza em argumentos insustentáveis e insuficientes diante da presença de variáveis e dimensões múltiplas. As tradicionais tentativas teóricas de conhecimento e compreensão, tendo como base a decomposição da totalidade, dificultam, também nos ambientes da educação escolar, a ampla e complexa tarefa de construir conhecimentos pertinentes.

O fenômeno da eletrólise das moléculas da água a fragmenta nos seus elementos químicos constituintes: o gás hidrogênio e o gás oxigênio. Mas como explicar um todo líquido - água - como sendo o resultado da soma de dois gases? Ou seja, a lógica de que a "soma das partes é igual ao todo" é simplesmente insuficiente, pois algo a mais emerge da organização de dois moles de hidrogênio e um mol de oxigênio, pois, nesse caso, gás mais gás não se reduz a um simples gás, mas origina um líquido. São essas emergências, presentes nas inter-retro-ações das organizações, que o pensamento complexo quer conhecer e compreender e é isso que podemos denominar de conhecimento pertinente.

É nesse sentido que o pensamento complexo pode ser validado como princípio epistemológico de diferentes estratégias pedagógicas. Entenda-se que a complexidade não exclui os princípios da ciência clássica quanto à ordem, à lógica e à separabilidade, no entanto procura alternativas de visualização e compreensão das dinâmicas emergentes da e na organização, para além de sequencialidades e justaposições. Em toda obra de Morin perpassa um compromisso com a questão do conhecimento, e ele o afirma escrevendo: "O problema cognitivo é o problema quotidiano de cada um e de todos. A sua importância política, social e histórica torna-se decisiva." (MORIN, 1992, p. 221). Diante de realidades complexas, a simples descrição analítica e a explicação com base em modelos simplificadores, analisando cada parte sem descrever o todo, e vice-versa, não possibilitam conhecimentos pertinentes.

A fragmentação do conhecimento em componentes curriculares oportuniza também que cada um deles crie seu próprio território de saber e poder, generalizando e se especializando em pedaços de saberes. Insiste-se na cegueira daquilo que exprime o surgimento do inédito e do inesperado. Por isso Morin (2003, p. 260) afirma que "O 
todo é uma macrounidade, mas as partes não estão fundidas ou confundidas nele; tem uma dupla identidade, identidade própria que permanece (portanto, não redutível ao todo) identidade comum, a da sua cidadania sistêmica." Essa característica constitui um circuito ativo, um jogo no qual o todo e as partes não se reduzem um ao outro, mas se complementam.

O todo é maior que a soma das partes já que contém propriedades que somente se manifestam nessa conjuntura. É, por exemplo, o que pode acontecer quando se possibilita a abertura para o conversar com outras áreas do saber. Também o todo é menos do que a soma das partes, se no momento da organização de umas com as outras houver a inibição de algumas de suas propriedades ou de alguma(s) singularidade(s). Quando tentamos olhar somente o todo estamos deixando de ver especificidades que somente se encontram nas individualidades. Também Morin (2003) afirma que o todo é mais do que o todo, porque em um movimento recíproco o todo fomenta o desenvolvimento das partes, assim como as partes contribuem para o desenvolvimento do todo que se refaz em novos patamares. Esse último aspecto pode ser comparado ao ambiente escolar, na medida em que o professor, que ensina, também aprende, e o mesmo acontece com os alunos; uma coparticipação como dinâmica de diversas interações complexas entre a unidade e a diversidade com predisposição para aprender a compreender a complexidade da vida, do ser humano, do conhecimento.

"Trata-se, ao mesmo tempo, de reconhecer a unidade dentro do diverso, o diverso dentro da unidade, de reconhecer, por exemplo, a unidade humana em meio às diversidades individuais e culturais, as diversidades individuais e culturais em meio à unidade humana." (MORIN, 2004, p. 25). É a unidade na diversidade que oportuniza considerar as emergências inscritas nos fenômenos da natureza, nos fenômenos biológicos como resultantes do acaso, do ruído e da presença das desordens e bifurcações. Possibilita reconhecer que as emergências, de ordem física ou sociocultural, são sempre inesperadas e incertas. Acaso, ruídos e incertezas são decorrências da dinâmica do movimento da ordem e da desordem e das emergências que dele fluem.

A dinâmica das interações permitiu a Morin (2005) a concepção da Unitas multiplex. Por meio dessa expressão o autor reconhece e deseja compreender a importância das interações entre o uno e o múltiplo, ou/e ao mesmo tempo do todo e das partes. É um foco epistemológico formulado para captar e compreender a complexidade inerente às realidades em si. No contexto da Unitas multiplex o universo físico e cultural, incluído o ser humano é um todo complexo e não pode ser compreendido de forma apropriada quando reduzido a regras e modelos simplificadores. A Unitas 
multiplex evidencia a necessidade de um pensamento complexo para compreensões mais amplas daquilo que, por natureza, é complexo. Por isso "[...] a ideia de unidade complexa adquire densidade se pressentimos que não podemos reduzir nem o todo às partes, nem as partes ao todo [...] mas que precisamos conceber em conjunto, de modo complementar e antagônico, as noções de todo e de partes, de um e de diversos." (MORIN, 2002 p. 135).

Complexidade é um convite para reunir, como complementares e não existentes separadamente, noções que na visão simplista foram e são separadas: uno-múltiplo, todo-partes, bem-mal, sujeito-objeto, ordem-desordem, certeza-incerteza, completude-incompletude. Esses pares binários, antagônicos na lógica da modernidade, são agora entendidos como complementares, em contextos dinâmicos de implicações mútuas em (re)organizações.

Essa concepção da dinâmica organizativa estava ausente da ciência moderna que tinha como referência os princípios da redução e disjunção, um paradigma simplificador com uma visão que considerava ser a natureza sólida, governada pelo princípio da estabilidade e da ordem. Para Morin (2002, p. 126), “[...] talvez não exista a última ou primeira realidade indivisível ou isolável, mas um continuum (teoria do bootstrap),${ }^{4}$ e até uma raiz unitária fora do tempo e do espaço.” Isso significa um novo olhar sobre o universo. Não pensamos mais na menor partícula ou unidade indivisível, mas no conjunto que todo o universo representa, em um sistema complexo que se auto-organiza.

Na obra O fim das certezas: tempo, caos e as leis da natureza, Prigogine (1996) apresenta uma nova racionalidade filosófica e científica que sinaliza para o fim das certezas. Para o autor, a lógica científica da modernidade e seu sustento na certeza das leis físicas e a consequente garantia da previsibilidade do futuro e do conhecimento certo estão equivocadas. Para ele, "A ciência clássica privilegiava a ordem, a estabilidade, ao passo que em todos os níveis de observação reconhecemos agora o papel primordial das flutuações e da instabilidade." (PRIGOGINE, 1996, p. 12). Se existem flutuações e instabilidades, então, o absoluto e o "em-si”" das coisas dão lugar às dinâmicas processuais nas quais a organização e a auto-organização terão lugar de destaque.

\footnotetext{
${ }^{4}$ A teoria bootstrap (presilha de bota), iniciada e defendida por Geoffrey Chew, não aceita a ideia da existência de constituintes fundamentais da matéria, como também não aceita quaisquer espécies de entidades fundamentais - nenhuma constante, lei ou equação fundamental. $\mathrm{Na}$ abordagem boostrap o universo é visto como uma teia dinâmica de eventos inter-relacionados. Nenhuma das propriedades de qualquer parte dessa teia é fundamental, todas elas decorrem das propriedades das outras partes do todo, e a coerência total de suas inter-relações determina a estrutura da teia (CAPRA, 2000).
} 
Na ciência clássica, baseada em uma lógica estrutural que não comportava a desordem, o sentido de organização era desconsiderado. Com o emergir da desordem também ressurge a organização. Mas, o que se entende por organização? “[...] a organização é o encadeamento de relações entre componentes ou indivíduos que produz uma unidade complexa ou sistema, dotada de qualidades desconhecidas quanto aos componentes ou indivíduos." (MORIN, 2002, p. 133). O autor sustenta que na organização existe um circuito trinitário: a organização que acontece por meio de processos de ordem e desordem constituindo uma inter-relação que por sua vez possibilita a constituição do sistema. As três noções apresentam-se indissociáveis, porém distinguíveis, remetendo-nos a pensar novamente no conceito Unitas multiplex, ou seja, em uma dinâmica de interdependência.

Na interdependência consideramos o uno e o múltiplo em uma relação mútua, na qual a imprevisibilidade, a contradição e a criatividade das e nas inter-relações podem emergir. Ordem e desordem coexistem, e, embora possamos, em um dado fenômeno, verificar regularidades e repetições, também se pode prever a ocorrência de desvios e irregularidades que, ocasionais ou não, fazem parte do contexto do fenômeno.

A complexidade possibilita um jeito de ser e estar não previsível, que oportuniza o reconhecimento do desconhecido, o reconhecimento dos limites dos conhecimentos, ao mesmo tempo em que impulsiona a curiosidade para novas descobertas. Um conhecimento não mais emanado das coisas e dos fenômenos, mas resultado de um amplo exercício reflexivo e recorrente e, por isso mesmo, recheado de afirmações provisórias e questionáveis, distantes e negando posições dogmáticas, determinadas e últimas.

Diferentemente do caminho pronto e estável, a complexidade abre-nos a possibilidade participativa e tem na incompletude e na imprevisibilidade do caminhar e da chegada a sua dinâmica mais intensa. Isso significa pervagar na obscuridade do conhecido em aliança com o desconhecido, do construído e do em construção. Na nebulosa viagem pelo desconhecido, já não existe um foco único, uma verdade única, uma luz indicativa da certeza, mas penetramos em um ambiente como um todo, incógnito e que nos interpela, como afirma Agamben (2009). Permitir-se ser interpelado é, para Agamben (2009), ser contemporâneo, é visualizar a complexidade do universo, como um escuro que não é " [.... a simples ausência da luz, algo como uma não visão, mas o resultado da atividade das off-cells, um produto da nossa retina."

Ao contrário da clareza e da ordem, experimentamos o desafio de enxergar sob a penumbra. Assim, a complexidade comporta a multidimensionalidade e não 
exclui a segurança de caminhar sob a projeção da luz, mas nos aproxima das variáveis e dos diversos significados que a penumbra pode provocar ao observarmos um fenômeno. Sabemos que a luz, ao atingir determinado objeto, clarifica uma das faces, mas deixa as demais encobertas pela penumbra. O que o pensamento complexo nos propõe é uma percepção para além do aparente, uma visão capaz de compreender o entrelaçamento das diferentes linguagens para a compreensão de um fenômeno. Isso significa que na complexidade se abrem oportunidades para as mais diversas visões sobre determinado fenômeno, desestabilizando o caminho pronto, único e verdadeiro.

A complexidade é uma oportunidade contrária à submissão dos conteúdos curriculares e das relações pedagógicas à tirania da fragmentação e da verdade absoluta. É uma oportunidade para perceber que o "todo tecido junto", a interdependência e a Unitas multiplex são o escuro não como “[...] uma forma de inércia ou de passividade, mas implica uma atividade e uma habilidade particular" para reavivar ambientes pedagógicos e educativos descobrindo "[...] as suas trevas, o seu escuro especial, que não é, no entanto, separável daquelas luzes." (AGAMBEN, 2009, p. 63). De suas concepções amplas e abertas abrem-se as portas para a emergência da transdisciplinaridade, indicativo de que podemos nos relacionar com o mundo de diferentes formas, engendrando as diferentes áreas do conhecimento nos processos de aprendizagem. Um convite para atitudes de humildade diante dos inúmeros saberes e como anúncio de efetiva participação, esta como fundamental nas relações pedagógicas em substituição à persistência no individualismo e no personalismo profissional e disciplinar.

\section{TRANSDISCIPLINARIDADE E ENVOLVIMENTO COLABORATIVO}

Com a emergência do paradigma da complexidade surge a necessidade de ultrapassar a tradicional forma de educar e também de revisar os alicerces epistemológicos que sustentam as práticas educacionais e lhes dão sentido. O simplismo do paradigma cartesiano já não é suficiente para atender à demanda educacional, política, social e ética nos cenários complexos da contemporaneidade, já que

\footnotetext{
Os grandes problemas políticos do mundo contemporâneo referem-se ao desarmamento, aos equilíbrios ecológicos, às mutações da economia e do trabalho, ao desenvolvimento dos países do hemisfério sul, à educação, à miséria, à manutenção do laço social etc. Ninguém possui a solução simples e definitiva para resolvê-los. [...] Além disso, os problemas em questão estão todos, em maior ou menor medida, interconectados em um espaço mundializado. Enfim, sua resolução exige negociações entre
} 
atores muito numerosos, de porte, cultura e interesses a curto prazo heterogêneos. Praticamente nenhum sistema de governo contemporâneo foi concebido de modo a responder a tais exigências. (LÉVY, 1998, p. 61).

Também, para Morin (2004), quanto mais os problemas se tornam multidimensionais, mais difícil é para pensá-los. Quer dizer que o retalhamento que ocorreu com a divisão do conhecimento em disciplinas torna impossível compreender o que é tecido junto. Se por um lado os desenvolvimentos disciplinares das ciências nos oportunizaram novas formas de organização e divisão do trabalho, por outro, levaram-nos aos inconvenientes do individualismo e do confinamento. O isolamento causa a cegueira e a ilusão da unidimensionalidade e autossuficiência, atrofiando diálogos produtivos entre disciplinas e entre seres humanos. Dessa forma, segundo proposição de Morin (2013, p. 194), um diferente desafio da educação “[...] ensinaria uma concepção complexificada dos termos aparentemente evidentes, não apenas de racionalidade, mas também de cientificidade, de complexidade, de modernidade, de desenvolvimento."

Conhecer e compreender essas concepções complexificadas é também entender que as experiências humanas, além de históricas, estão circunscritas não na exclusiva certeza e clareza do conhecimento, mas comportam também fronteiras misteriosas, recheadas de incertezas e ambiguidades. Permite compreender que todas as experiências de conhecimentos antropológicos, filosóficos, sociológicos e outros resultam de interpretações a partir de sistemas de pensamentos que entrelaçam a construção da condição humana de forma interdependente, envolvente e envolvida em seu universo existencial. Se "Conhecer o humano não é separá-lo do universo, mas situá-lo nele" (MORIN, 2004, p. 37), já não cabe a versão antropocêntrica, mas reconhecer que o ser humano se encontra em constante interação com o universo; interação que possibilita reconhecer ser a condição humana resultado de ações colaborativas.

Então, também como perspectiva pedagógica se coloca o desafio da colaboração entre disciplinas, como forma de fecundar as reflexões das possibilidades de conhecer os conhecimentos, fecundidade da qual pode emergir uma inteligência coletiva, como expressa Lévy (1998), permitindo reconhecer a pertinência do entrelaçamento de diferentes discursos, conversas, reflexões e escutas. Implica uma ressignificação epistemológica e cultural assentada no pressuposto de que "[...] na sociedade estão em jogo muitas linguagens diferentes e uma imensa gama de elementos heterogêneos, incongruências e incredulidades que inviabilizam uma saída salvadora e única." (GOERGEN, 2012, p. 158). 
Para Lévy (1998, p. 17), a mobilização colaborativa possibilita o reconhecimento da responsabilidade mútua, pois "Se nos engajássemos na via da inteligência coletiva, progressivamente inventaríamos as técnicas, os sistemas de signos, as formas de organização social e de regulação que nos permitiriam pensar em conjunto." Uma forma de os especialistas contribuírem para um processo de construção colaborativa em uma versão diferente da descrita por Nicolescu (1999, p. 51):

Dois especialistas na mesma disciplina têm, hoje em dia, dificuldade em compreender seus resultados recíprocos. Isso nada tem de monstruoso, na medida em que é a inteligência coletiva da comunidade ligada a esta disciplina que a faz progredir e não um único cérebro que teria de conhecer todos os resultados de todos seus colegas cérebros, o que é impossível. Pois, hoje em dia, existem centenas de disciplinas. Como poderia um físico teórico em partículas dialogar com um neurofisiologista, um matemático com um poeta, um biólogo com um economista, um político com um especialista em informática, exceto sobre generalidades mais ou menos banais?

A compartimentalização do conhecimento, em forma de disciplinas, contribui para a hiperspecialização, dificulta o diálogo produtivo e determina territórios como agregados competitivos. Para Popper (1972, p. 95-96):

\begin{abstract}
A idéia de que a física, a biologia e a arqueologia existem por si mesmas, como campos de estudos ou disciplinas distinguíveis entre si pela matéria que investigam, parece-me resíduo da época em que se acreditava que qualquer teoria precisava partir de uma definição do seu próprio conteúdo. Na verdade não é possível distinguir disciplinas em função da matéria de que tratam; elas se distinguem umas das outras em parte por razões históricas e conveniências administrativas (como a organização do ensino e do corpo docente), em parte as teorias que formulamos para solucionar nossos problemas têm a tendência de se desenvolver sob a forma de sistemas unificados.
\end{abstract}

Organizações disciplinares fechadas tendem a impedir os avanços de ações pedagógicas colaborativas e persistem na oferta de mecanismos formativos defasados e sem ênfase na compreensão dos conhecimentos, sequer na compreensão das condições e experiências de vida. Por isso, Nicolescu (1999) afirma ser necessário cometer o "sacrilégio" de cruzar as fronteiras da própria disciplina e visualizar uma ponte que possibilita estudar fenômenos situados fora e além do âmbito disciplinar.

Esse "sacrilégio" poderá qualificar as ações pedagógicas e educacionais, o que significa contribuir para que o ser humano seja capaz de conhecer melhor o 
mundo em que vive, compreendendo os fenômenos do mundo, da natureza e da humanidade. Essa requalificação do cenário pedagógico pode ser potencializada pela transdisciplinaridade, esta que significa o "[...] que está acima das disciplinas [...] que transcende ou abrange as disciplinas, [sendo mais completa e complexa do que a interdisciplinaridade] que liga as disciplinas.” (NICOLESCU, 1999).

Trata-se de uma visão diferente da proposta pela educação simplificadora, dogmática e disciplinar, por atrofiar a aptidão de contextualizar os conhecimentos e valorizar muito mais a separação que a associação de ideias em um todo significativo.

O termo transdisciplinaridade foi usado por Piaget em 1970 em um congresso sobre interdisciplinaridade ao afirmar que a etapa interdisciplinar deveria ser sucedida por outra de caráter transdisciplinar. A visão da transdisciplinaridade tem origem no teorema de Gödel, proposto em 1931, visando distinguir a existência de vários níveis de realidade e não somente de um nível, como o dogma da lógica clássica em seu axioma do Terceiro Excluído afirmava: “[...] não há um termo T, que é, ao mesmo tempo, A e não-A. [A existência de] um terceiro termo T, que, ao mesmo tempo, é A e não-A" (NICOLESCU, 1999, p. 29) leva a outro nível de realidade, diferente do nível anterior, nos termos da lógica da não contradição. Abre-se uma janela de possibilidades para novas e diferentes visões das realidades.

A transdisciplinaridade não elimina a multidisciplinaridade, a pluridisciplinaridade, a interdisciplinaridade e nem mesmo a disciplinaridade, pois ela emerge da necessidade de complementar essas dinâmicas trazendo à tona um olhar para realidades multidimensionais e multirreferenciais que têm a colaboração como pressuposto fundamental. "A disciplinaridade, a pluridisciplinaridade, a interdisciplinaridade e a transdisciplinaridade são as quatro flechas de um único e mesmo arco: o do conhecimento" (NICOLESCU, 1999, p. 55), porque a compreensão das realidades ascende a outros níveis com significados mais abrangentes e abertos para novos processos.

A atitude transdisciplinar traduz a necessidade indispensável de encontrar princípios e vínculos de unidade entre as diferentes ciências e diferentes disciplinas. Ela implica uma atitude epistemológica que, ao mesmo tempo em que junta e visualiza articulações, procura superar as particularidades, conjugando os saberes para, a partir de diferentes aportes, perceber a complexidade do conhecimento. É uma abertura para reflexões complexas, não conclusivas, pois o pensar complexo nos diz que o conhecimento nunca estará completo e que a racionalidade tem limites.

A transdisciplinaridade não visa ao conhecimento total, mas aspira saberes menos particulares e compreende cada vez mais que conhecer o conhecimento é exi- 
gência de um processo repleto de variáveis complexas e inseparáveis. Essa abertura e envolvimento com varáveis complexas comporta a aceitação do desconhecido, do inesperado e do imprevisível. São atitudes epistemológicas que refletem avanços no processo de construção de conhecimentos, cujos novos patamares evidenciam os limites que as disciplinas apresentam para a compreensão dos fenômenos do mundo, da natureza e da humanidade.

Para Nicolescu (1994, p. 3), enquanto

Todo o conhecimento ocidental assenta sobre a eficácia da especialização, o que é uma ideia justa [...] a Transdisciplinaridade não é uma nova disciplina, não diz respeito nem ao método, nem à justaposição de conhecimentos que fazem parte de uma disciplina já existente. É, antes, uma atitude rigorosa em relação a tudo o que se encontra no espaço que não pertence a nenhuma disciplina.

Por isso, em termos pedagógicos e formativos, ela significa uma oportunidade para que os seres humanos - estudantes - sejam capazes de conhecer melhor o mundo em que vivem também com a percepção das tramas e dos envolvimentos presentes.

Um mundo reconhecidamente envolvido em fenômenos de maior complexidade exige para seu conhecimento concepções de natureza teórica e metodológica distintas, diversificadas e dispersas, mas interligadas e enredadas, possibilitando conhecimentos concebidos e frutos de uma rede de interconexões rizomáticas. Uma visão que considera insuficiente a formação linear e especializada, para uma formação mais geral capaz de aprendizagens colaborativas.

No artigo $3^{\circ}$ da Carta da Transdisciplinaridade lemos que ela

[...] é complementar à abordagem disciplinar; ela faz emergir do confronto das disciplinas novos dados que as articulam entre si; e ela nos oferece uma nova visão da Natureza e da Realidade. A Transdisciplinaridade não busca o domínio de várias disciplinas, mas a abertura de todas elas àquilo que as atravessa e as ultrapassa. (NICOLESCU, 1999, p. 148).

Então, a transdisciplinaridade implica abrir-se ao diálogo, questionar e questionar-se para verificar a autenticidade argumentativa das discussões. A atitude do diálogo possibilita reconhecer a legitimidade dos olhares de outras disciplinas, e a partir deles possibilitar a revisão das bases limitadoras de nossa própria disciplina. Para Flickinger (2010, p. 53), esse diálogo questionador “[...] não nos abre os olhos 
para enxergar melhor o que se passa em outras áreas, senão nos torna cada vez mais especialistas em nossa disciplina de origem. Somente assim se abre um leque mais amplo de conhecimentos, capaz de integrar os mais diversos acessos ao mundo."

É um estaleiro de acessos em forma de rede de referenciais de leitura de mundo em construção e reconstruindo a si mesmo nas interações com os colegas e pelo conhecimento. Essa rede de referenciais complexas sobre o significado de ser humano e sobre o processo de conhecimento, constitui e é constitutiva do paradigma educacional baseado na transdisciplinaridade. Ele oportuniza a organização de questões de estudo e investigações coletivas sobre determinado objeto ou fenômeno. $\mathrm{O}$ resultado será um conhecimento, fruto de uma rede de articulações que encontra na humildade do diálogo o alimento dos diferentes enfoques.

Humildade que possibilita a acolhida das contribuições de outro, como escreve Follmann (2005, p. 10, grifo nosso), já que a

[...] atitude transdisciplinar é, sobretudo, uma atitude de humildade, no sentido de estar sempre pronto para acolher a contribuição do outro. Posso dizer que tenho atitude trans se minha postura é de reconhecimento do outro e da possível pertinência de sua contribuição, para além dos meus limites e de minha imaginação.

Na posição de Folmann (2005), a atitude transdisciplinar, como atitude de humildade, implica a aceitação e o reconhecimento do direito às ideias e verdades, mesmo que contrárias às nossas. Existe uma premissa fundamentando o respeito ao modo de ser de cada um, ao modo como cada um se envolve na aprendizagem e se faz ser humano em convivência. Ou seja, como atitude transdisciplinar se entende que a sala de aula é muito mais o encontro entre indivíduos do que entre disciplinas. A atitude de humildade, que permite aceitar o diferente, também possibilita aceitar a diferença entre as disciplinas e reconhecer sua responsabilidade mútua. Morin (2004, p. 18) foi enfático ao afirmar que a fragilização de percepções globais também fragiliza "[...] o senso de responsabilidade - cada um tende a ser responsável apenas por sua tarefa especializada -, bem como ao enfraquecimento da solidariedade - ninguém mais preserva seu elo orgânico com a cidade" e nem com os demais seres humanos. A atitude de humildade, tendo o diálogo como exigência das formas relacionais entre pessoas e entre disciplinas, faz da abordagem transdisciplinar um desafio inerente capaz de estabelecer inter-relações das diversas complexidades, dos diferentes níveis de realidade e contextos. 
Essa (co)responsabilidade no processo de aprendizagem estende-se para o universo da solidariedade, um indicativo para compromissos coletivos para com as urgentes mudanças nas diversas organizações humanas, como escreve Trocmé-Fabre (2005, p. 6, grifo do autor): a transdisciplinaridade oferece à escola “[...] a ocasião e os meios de ser um imenso terreno no qual o aprendizado tem a possibilidade de se tornar um elemento responsável e parceiro da mudança social, econômica e política da qual o planeta necessita crucialmente."

A transdisciplinaridade, como base das ações pedagógicas, expressa a complexidade do ser humano, a complexidade social econômica e política. Os padrões de aluno, de sociedade, de economia ou de conhecimentos prefigurados, caros para a modernidade, não passam de abstrações e equívocos conceituais. Na atualidade, a interdependência, os envolvimentos e as interconexões são partes dos desafios de diversas disciplinas escolares a construírem diferentes olhares sobre o ser humano, a natureza e o próprio conhecimento.

Trocmé-Fabre (2005) lembra que o ser humano, como sistema vivo, tem como primado a exigência da presença e da proximidade, a exigência de se auto-organizar e de se auto-estruturar. É, então, fundamental que o sentido e as responsabilidades educativas criem ambientes e condições favoráveis para experiências de aprendizagens capazes de organizar envolvimentos e interações, possibilitando parcerias com o coração do ser e estar vivo. Também viabilizar a emergência do conversar que tem na colaboração a exigência de levar o outro a sério para encontrar princípios convergentes entre culturas, nações, religiões e relações eco-ambientais.

Se, como escreveu Margulis (2001, p. 106),

A vida é uma interdependência incrivelmente complexa de matéria e energia entre milhões de espécies fora (e dentro) de nossa própria pele. Esses estranhos da Terra são nossos parentes, nossos ancestrais, e parte de nós. Eles reciclam nossa matéria e nos trazem água e alimento. Não sobrevivemos sem "o outro". Nosso passado simbiótico, interativo e interdependente, é interligado por águas agitadas.

A colaboração somente e exclusivamente é possível nas relações de respeito mútuo. E o respeito mútuo acontece fora das relações hierárquicas, fora das relações de dominação, de submissão, subserviência e obediência. Para Maturana (1998), foi um modo de vida em colaboração e compartilhamento que originou a linguagem e com ela a aventura da humanização. Conforme o autor, a condição humana, as raízes da humanização se fundamentam na colaboração, tendo nela sua fonte originária. 
[...] o humano se constitui na história dos primatas bípedes à qual pertencemos, com a origem da linguagem. E a linguagem se origina em uma certa intimidade do viver cotidiano, no qual esses nossos antepassados conviviam compartilhando alimentos, na sensualidade [...] na participação dos machos na criação das crianças [...] E ali surge a linguagem como um domínio de coordenações de coordenações consensuais de conduta. (MATURANA, 1998, p. 46).

A transdiscipinaridade é uma oportunidade de religação aos primórdios do processo de humanização, uma possibilidade de transformar a sala de aula em um ambiente de respeito mútuo, de corresponsabilidade aprendente e de experiências formativas na convivialidade. A experiência da atitude transdisciplinar pode ser uma oportunidade para que no futuro, como pessoas adultas, as hoje crianças e adolescentes não vivam a alienação dos fundamentos da humanização, não vivam na priorização da alienação da apropriação, do poder, das hierarquias, dos ódios e da indiferença. É uma oportunidade para viver em espaços de coexistência nos quais a aceitação da legitimidade de todas as formas de vida e da possibilidade de consensos possibilitam a "[...] geração de um projeto comum de convivência." (MATURANA; DÁVILA YÁÑEZ, 2009, p. 107). A atitude transdisciplinar nos abre a possibilidade de compreender tanto a vida quanto a natureza como emergências sistêmicas e a oportunidade para visualizar e vivenciar a interação, a coparticipação e a colaboração. Significa também avançar o conhecimento científico na perspectiva de uma concepção de racionalidade mais ampla, capaz de contemplar o ser humano, a vida em geral e a natureza como unidades interativas, colaborativas e criativas em vez de dissociadas.

Para Capra (1997, p. 193, grifo nosso), em A teia da vida

O reconhecimento da simbiose como uma força evolutiva importante tem profundas implicações filosóficas. Todos os organismos maiores, inclusive nos mesmos, são testemunhas vivas do fato de que práticas destrutivas não funcionam a longo prazo. No fim os agressores sempre destroem a si mesmos, abrindo caminho para outros que sabem como cooperar e como progredir. A vida é muito menos uma luta competitiva pela sobrevivencia do que triunfo da cooperação e da criatividade. $\mathrm{Na}$ verdade, desde a criação das primeiras células nucleadas, a evolução procedeu por meio de arranjos de colaboração e de co-evolução cada vez mais intrincados.

Na vida e nas convivências em colaboração, podemos recuperar a sensibilidade individual e coletiva, a cordialidade e o encantamento como forma de viver 
o e no autorrespeito e o e no respeito pelo outro. Na reflexão de Papst (2005), experiências educativas transdisciplinares não paralisam o desenvolvimento como ser humano. Crianças e estudantes não serão educados com o estigma de seres humanos deformados a carregarem por toda a vida os mais diversos tipos de danos mentais e psíquicos para viverem no desespero, na desolação e na perda de enraizamento. Por isso, escreve Papst (2005, p. 17):

As crianças devem ser levadas a sério em vista de suas expressões, esperanças e desejos, introspecções e temores individuais. Elas desenvolvem suas personalidades individuais no ambiente em que vivem e, ao mesmo tempo, elas mudam continuamente o ambiente além do que se pensa, de acordo com consistentes e bem inspiradas idéias que trazem.

Levar a sério o dizer de cada criança e de cada ser humano é proporcionar o desenvolvimento de reflexões a partir de diferentes lógicas que tornam possível o exercício de liberdade. Essa prática pedagógica, a partir da abordagem transdisciplinar, reconhece o aluno como um Terceiro Incluído e não mais como um Terceiro Excluído, como referendava a lógica absoluta da ciência tradicional.

Nas palavras de Maturana (2000, p. 104, grifo nosso),

Para transpormos fronteiras, precisamos de liberdade. Isso significa que temos de nos comportar de maneira que possamos emergir, sem que tenhamos medo de desaparecer no que fazemos. Assim, podemos voltar ou ficar lá; ou podemos ir além de juntar coisas que de outra maneira não seriam juntadas, porque campos diferentes não se relacionam, mas somos nós, seres humanos, que os relacionamos.

Uma relação pedagógica na qual o sujeito - estudante - é o ponto de partida. Na sensibilidade dessa relação a solidariedade se desenvolve entre os alunos que concebem ser a interligação com tudo e todos a fonte da responsabilidade. Responsabilidade de cada um por toda e qualquer ação individual ou coletiva, uma sensibilidade capaz de resgatar o sentido humano e social de que podemos saber juntos com foco na colaboração e na coevolução.

A abordagem transdisciplinar inverte a aposta na lógica da agressão que exclui, inverte a lógica da luta e da competição para reflexões e ações sem obsessão à fragmentação e ao controle, mas atenta às emergências da harmonia na congruência com outros seres humanos, com outros seres vivos e com o mundo natural, como sinaliza Maturana (1998, p. 34, grifo nosso): 
Não é a agressão a emoção fundamental que define o humano, mas o amar, a coexistência na aceitação do outro como um legítimo outro na convivência. Não é a luta o modo fundamental de relação humana, mas a colaboração. Falamos de competição e luta criando um viver em competição e luta, e não só entre nós, mas também com o meio natural que nos possibilita. Assim, dizem que os humanos devemos lutar e vencer as forças naturais para sobreviver, como se isso tenha sido e seja a forma normal do viver. Mas não é assim. A história da humanidade na guerra, na dominação que subjuga, e na apropriação que exclui e nega o outro, se origina no patriarcado [...] antes do patriarcado se vivia na harmonia com a natureza, no gozo da congruência com o mundo natural, na maravilha de sua beleza não na luta com ela.

Por fim, o convite transdisciplinar é um convite para olhares que transcendem as disciplinas individuais das ciências exatas, das ciências humanas e das ciências tecnológicas. Ela transcende a fragmentação, a lógica da hierarquia, do controle e da verdade absoluta. A abordagem transdisciplinar encoraja para religações pela via da sensibilidade, do encantamento pela condição humana. Encoraja para conceber visões e ações integradas umas com as outras, sem esquecer da presença de cada um e de todos em um ambiente de aprendizagem e de formação escolar. Para possibilitar a congruência consigo, com outros, com a natureza e com os conhecimentos, a abordagem transdisciplinar oportuniza aprendizagens com as quais se olha, escuta-se e se aprende sem o estigma da submissão, sem o estigma da não aceitação, da indiferença e da rejeição, nem da busca ansiosa por algo que não se é.

O caminhar aprendente e formativo, no seio da transdisciplinaridade, reconduz-nos ao envolvimento sem exigências, tanto na construção e reconstrução de conhecimentos pertinentes quanto na construção e reconstrução do humano no humano.

\section{CONSIDERAÇÕES FINAIS}

Em meio à profunda crise existencial, nosso anseio e necessidade gira em torno da procura por planos salvacionistas capazes de nos livrar das inúmeras adversidades vivenciais. Buscamos por receitas prontas, para facilitar o trabalho pedagógico e formativo e que, ao mesmo tempo, responda aos objetivos de um sentido mais humano para a vida de cada ser humano. Triste equívoco, descobrimos de maneira perversa que isso não é possível.

A desconstrução de ideais, como boa nova salvacionista, possibilita a emergência da complexidade e da transdisciplinaridade nas quais as interdependências são 
aberturas rizomáticas para também estratégias formativas e de aprendizagens processuais cujas fronteiras não objetivam fragmentar o ser humano, os conhecimentos, as aprendizagens e a vida. A complexidade tem sua âncora na existência de diferentes níveis de realidades, reconhece a organização sistêmica e interdependente, tanto das coisas do mundo natural quanto da vida e/ou das organizações humanas. A multidimensionalidade das realidades é cada vez mais indispensável, uma vez que quanto mais estreito e simplista for o nível de compreensão, menor e mais pobre será o sentido da vida humana.

A transdisciplinaridade é uma possibilidade de alargarmos a compreensão das realidades multidimensionais, pelo rigor das reflexões, pela abertura às diversas manifestações e pela aceitação da presença de um fundo auto-organizativo em cada ser humano. Reaprender a e pela transdisciplinaridade significa consagrar o diálogo entre diferentes campos de saber sem impor o domínio de uns sobre os outros. Firma alianças entre os profissionais e seus conhecimentos disciplinares para ações pedagógicas e formativas por meio de posturas de interação, aceitando a presença de competências individuais e coletivas. Mesmo tendo dificuldades de perceber a complexidade e as conexões visíveis e invisíveis que ela possibilita, confiamos na transdisciplinaridade, pois até mesmo sua etimologia nos propõe aberturas o que está entre, o que transita e o que extrapola o fragmentado, para reconhecer a interdependência.

Ações pedagógicas e formativas transdisciplinares transpassam os mecanismos do conhecido para evidenciarem a dúvida, a incerteza, as criatividades originais nos caminhares que se integram, complexamente, por diferentes e controversos contextos das realidades e da vida humana; uma formação que pode mobilizar a sensibilidade humana para vivenciar culturas diversificadas e complexas, porque cheias de vida.

A abordagem transdisciplinar é uma oportunidade para colocar em questão as lógicas hierárquicas e as normatizações curriculares e dar espaço ao rizomático, que aproxima, entrelaça e possibilita múltiplas e diferenciadas conexões entre os saberes. Ao mesmo tempo em que firma a interdependência entre os conhecimentos, ela é motivadora de uma diferente organização social, na qual a questão da solidariedade, recolocada, torna-se um indicador-guia para as convivências.

Assim, as leituras e reflexões envolvendo a complexidade e a transdisciplinaridade são janelas abertas para compreender o quão indispensável é reconhecer a interdependência para reavivar a condição humana. $\mathrm{O}$ ainda inconcluso sonho de humanidade, como nossa responsabilidade, reencontra-se no berço da colaboração, germina e se retroalimenta nos braços da solidariedade rizomática e no diálogo da aceitação de si e do outro. 


\section{REFERÊNCIAS}

AGAMBEN, G. O que é o contemporâneo? E outros ensaios. Chapecó: Argos, 2009.

CAPRA, F. A teia da vida: uma nova compreensão científica dos sistemas vivos. São Paulo: Cultrix, 1997.

CAPRA, F. O tao da física: um paralelo entre a física moderna e o misticismo oriental. São Paulo: Cultrix, 2000.

FLICKINGER, H.-G. A caminho de uma pedagogia hermenêutica. Campinas: Autores Associados, 2010.

FOLLMANN, J. I. A universidade exposta à transdisciplinaridade. Revista Instituto Humanitas Unisinos, São Leopoldo, p. 8-12, ago. 2005.

GELATI, F. C. Da complexidade da educação à educação da complexidade: em busca dos princípios educativos em Edgar Morin. 2010. 111 p. Dissertação (Mestrado em Educação)-Universidade do Oeste de Santa Catarina, Joaçaba, 2010.

GOERGEN, P. O embate modernidade/pós-modernidade e seu impacto sobre a teoria e a prática educacionais. Revista Eccos: Revista Científica, São Paulo, n. 28, p. 149-169, maio/ago. 2012.

LÉVY, P. A inteligência coletiva: por uma antropologia do ciberespaço. São Paulo: Loyola, 1998.

MARGULIS, L. O Planeta Simbiótico: uma nova perspectiva da evolução. Rio de Janeiro: Rocco, 2001.

MATURANA, H. Cognição e transdisplinaridade. In: MELLO, M. F.; BARROS, V. M.; SOMMERMANNN, A. (Org.). Educação e transdisciplinaridade. Brasília, DF: Unesco, 2000.

MATURANA, H.; DÁVILA YÁÑEZ, X. Habitar humano: em seis ensaios de Biologia Cultural. São Paulo: Palas Athena, 2009.

MATURANA, H. Emoções e linguagens na educação e na política. Belo Horizonte: Ed. UFMG, 1998.

MINAYO, M. C. S. Interdisciplinaridade: uma questão que atravessa o saber, o poder e o mundo vivido. Medicina, Ribeirão Preto, v. 24, n. 2, p. 70-77, abr./jun. 1991. 
MORIN, E. A cabeça bem-feita: repensar a reforma, reformar o pensamento. 10. ed. Rio de Janeiro: Bertrand Brasil, 2004

MORIN, E. A via para o futuro da humanidade. Rio de Janeiro: Bertrand Brasil, 2013.

MORIN, E. Ciência com consciência. 7. ed. Rio de Janeiro: Bertrand Brasil, 2003.

MORIN, E. O método 1: a natureza da natureza. Porto Alegre: Sulina, 2002.

MORIN, E. O método IV. As idéias: a sua natureza, vida, habitat e organização. Lisboa: Europa-América, 1992.

MORIN, E. Os sete saberes necessários à educação do futuro. 10. ed. São Paulo: Cortez, 2005.

NICOLESCU, B. A visão do que há entre e além. Diário de Notícias, Lisboa, caderno cultura, 03 fev. 1994. Entrevista concedida a Antónia de Sousa.

NICOLESCU, B. O manifesto da transdisciplinaridade. Tradução Lucia Pereira de Souza. 3. ed. São Paulo: Triom, 1999.

PAPST, J. Tornar todos os saberes acessíveis para todos em toda a parte. Revista do Instituto Humanitas Unisinos, São Leopoldo, p. 12-14, ago. 2005.

POPPER, K. R. Conjecturas e refutações. Brasília, DF: Ed. Universidade de Brasília, 1972.

PRIGOGINE, I. O fim das certezas: tempo, caos e as leis da natureza. São Paulo: Universidade Estadual Paulista, 1996.

TROCMÉ-FABRE, H. A universidade exposta à transdisciplinaridade. Revista do Instituto Humanitas Unisinos, São Leopoldo, p. 4-7, ago. 2005.

Recebido em: 07 de abril de 2016 Aceito em: 13 de dezembro de 2016

Endereço para correspondência: Rua Getúlio Vargas, 2125, Bairro Flor da Serra, Joaçaba, Santa Catarina, Brasil; roque.strieder@unoesc.edu.br 
